\title{
Las relaciones de enamoramiento y de sexualidad entre los jóvenes de la Universidad Nacional del Centro del Perú
}

\section{The relationships of falling in love and sexuality among the youth of the Na- tional University of the Center of Peru}

\author{
Freder L. Arredondo B. ${ }^{(1)}$ y Carlos A. Romero S. ${ }^{(1)}$ \\ (1) Facultad de Antropologia, Universidad Nacional del Centro del Perú \\ Email: farredondo@uncp.edu.pe y cromero@uncp.edu.pe
}

\section{RESUMEN}

El presente estudio tiene como objetivo investigar los elementos sociales y culturales que componen las relaciones de enamoramiento y de sexualidad entre los jóvenes de la Universidad Nacional del Centro del Perú. Se utilizó una metodología mixta, el método cualitativo de la hermenéutica y el método cuantitativo de la estadística, teniendo mayor preferencia por el primero, para la interpretación de los testimonios de los actores sociales de estudio. Se encuestó a 60 estudiantes universitarios masculinos y femeninos. Los datos obtenidos se interpretaron en relación con la teoría del género existente sobre el tema. Los resultados muestran que los universitarios han logrado un avance en el campo de la sexualidad y el amor frente a sus parejas.

Palabras Claves: Relaciones de enamoramieno - relaciones de sexualidad - Características sociales y culturales - Estudiantes universitarios.

\begin{abstract}
The research aims to investigate the social and cultural elements that make up the relationships of love and sexuality among young people of the National University of Central Peru. A mixed methodology was used, the qualitative method of hermeneutics and the quantitative method of statistics, having a greater preference for the first, for the interpretation of the testimonies of the social actors of study. 60 male and female university students were surveyed. The data obtained were interpreted in relation to the existing gender theory on the subject. The results show that university students have achieved an advance in the field of sexuality and love in front of their partners.
\end{abstract}

Keywords: Relationships in love - sexuality relationships - social and cultural characteristics - university students. 


\section{INTRODUCCIÓN}

Dentro de la tradición de los estudios antropológicos, la investigación sobre la familia y el matrimonio; así como, las relaciones de parentesco, han sido los ejes principales a través de los cuales esta ciencia se ha desenvuelto desde sus inicios. A tal punto que, una de sus figuras más conspicuas asevero que "la antropología es el estudio de un hombre abrazado a una mujer" (Malinowski), reflejando lo importancia de la pareja y del matrimonio.

Desde el inicio de la humanidad las personas han establecido relaciones sociales entre ellas, una de las más importantes es la relación de parejas que da inicio a la constitución de una familia, estas relaciones han presentado diferentes formas y han ido cambiando a través del tiempo y el espacio.

Este proceso es dinámico y cambiante, y ha sufrido transformaciones en el tiempo. En la actualidad, se considera como normal y se ha naturalizado en matrimonio monógamo y heterosexual, revestido por un amor romántico y confluyente, entre un hombre y una mujer (Giddens, 2012); aunque en las últimas décadas, se ha cuestionado este hecho desde la teoría social, como desde los estudios de género y desde algunos colectivos que actúan políticamente.

Se piensa también, desde hace unas décadas, que la sexualidad y el enamoramiento, entre individuos era más recatado y respetuoso, repleta de formalidad, hasta que se ha llegado a un punto, actual, en la que se señala que estas relaciones son temporales y pasajeras, más abiertas y libres por señalarles algunas características; esta situación, tiene un directo efecto e impacto en la familia y, por tanto, en la sociedad.

Lo que interesa en la investigación, es la manera de cómo dos personas jóvenes deciden unirse, debido a que antes de una formalización, hay un proceso de atracción y enamoramiento, repleto de símbolos y elementos culturales, entre personas; esta es una característica trascendental en la vida de hombres y mujeres.

En los últimos años, se percibe que estas relaciones van sufriendo grandes transformaciones, las formas de enamoramiento y la concepción misma de sentimientos, como el afecto, el cariño, las emociones, anhelos, infidelidades, la ternura y el amor están siendo sometidas a reconfiguraciones y a cambios nunca antes visto.

Estos comportamientos tienen un impacto en las personas mayores, psicólogos, educadores, sexólogos, medios de comunicación, entre otros. Es común escuchar y leer, a manera de crítica y reproche, que la juventud antes que un compromiso serio revestido de amor, busca solo placer sexual momentáneo. Se señala que los jóvenes, de ambos géneros, no están preparados para estas situaciones; sin embargo, la vida continua y los jóvenes se van relacionando con sus parejas al margen de las opiniones y hasta de las descalificaciones de su conducta amorosa.
El problema de investigación que se ha planteado es la siguiente: ¿Qué características sociales y culturales tienen las relaciones de enamoramiento y de sexualidad entre los jóvenes de la Universidad Nacional del Centro del Perú? Teniendo como objetivo: investigar los elementos sociales y culturales que constituyen las relaciones de enamoramiento y sexualidad entre los jóvenes de la Universidad Nacional del Centro del Perú.

\section{MATERIALES Y MÉTODOS}

Se utilizó una metodología mixta; el método cualitativo de la hermenéutica y el método cuantitativo de la estadística, teniendo mayor preferencia por el primero, para la interpretación de los testimonios de los actores sociales de estudio. Se elaboró un cuestionario de preguntas abiertas y cerradas, para una muestra no probabilística de 60 estudiantes de ambos sexos de distintas facultades de la Universidad Nacional del Centro del Perú.

\section{RESULTADOS}

\section{Sobre el amor}

a. ¿Cómo concibes el amor de pareja? (definición) Una de las principales ideas de los jóvenes es que se trata de un sentimiento que corresponde a dos personas que se relacionan mutuamente, donde la fidelidad y el respeto son dos elementos principales. Uno de los testimonios, refiere la necesidad de ser detallista y amoroso con la pareja, mientras que las señoritas indican que el amor espera, respeta y no hace nada y es sacrificado; también hace mención al respeto como, a la fidelidad, a la confianza y al cariño, lo que coincide con la opinión de los jóvenes respecto a la reciprocidad de este sentimiento. Se refiere que el enamoramiento debe ser físico con el aspecto "interior"; además, el amor pasa por etapas, es un proceso, el enamoramiento, noviazgo, la consolidación o convivencia y el matrimonio.

Mediante los testimonios, se puede encontrar algunos aspectos que resaltan y contrastan con la teoría sobre el tema, ser detallista conlleva a tomar un rol protagónico frente a un rol más pasivo de la dama, mientras que las señoritas asumen un rol marianista (en relación a la figura católica de María), con las palabras que utilizan para adjetivar al amor "espera, respeta, no hace nada y es sacrificado".

Profundizando la interpretación, se puede indicar que en esta época ha triunfado el amor romántico entre el hombre y la mujer. Las novelas, películas, canciones y poemas, relatan historias de hombres y mujeres enamorados, donde a través de dramas y tragedias se reproducen historias de amor, que sirven de modelo a las generaciones jóvenes; pero estos modelos; no son neutrales sino reproducen jerarquías sociales y se establecen relaciones de poder con respecto al amor romántico. 
Concebir al amor como un proceso, otorga sustento a la afirmación que el amor romántico es una construcción socio cultural, porque estos han variado con el transcurso del tiempo, tampoco estas etapas se cumplen inexorablemente en todos los casos.

b. ¿Crees que el amor de pareja es exclusivo (solo se puede amar a una pareja) o se puede amar a otras personas?

Los testimonios de los jóvenes son claros, se puede querer a muchas, pero amar a una sola, refleja la posibilidad y la permisibilidad de poder tener varias parejas, aunque solo se ama una sola. Una característica del amor romántico es compartir con una pareja toda la vida, reflejando el discurso religioso, "hasta que la muerte nos separe", una idealización del amor. Además, se reconoce la diversidad y la diferencia de experiencias con cada relación. Para los jóvenes la sinceridad, característica del amor entra en conflicto con la no exclusividad en esta relación.

Para las universitarias es un signo de inmadurez y de falta de autoestima que una persona tenga más de una pareja. Resaltan el tema de exclusividad y de un amor total, no a medias. No existe ninguna posibilidad para ellas de que una persona pueda amar a otra. Toda la atención debe estar enfocada en la pareja.

c. ¿Crees que el amor es para siempre, "hasta que la muerte los separe”? ¿Por qué?

Hay jóvenes que diferencian el amor de la costumbre; el primero, como una pasión intensa, pero temporal, mientras que la segunda, algo que ya se ha hecho habitual y cotidiano por la repetición y el tiempo. Además, son conscientes que la mayor parte de las parejas que se forma en la actualidad tienen una menor duración que las parejas de las generaciones anteriores, este hecho lo atribuyen a la inseguridad de las personas.

Mencionan que ahora hay mayor promiscuidad sexual; por esa razón, hay jóvenes que se embarazan a temprana edad.

Las universitarias no creen que el amor sea para siempre, porque creen que el amor tiene un comienzo y un fin, que este sentimiento cumple un ciclo, y argumentan que en estas relaciones se presentan conflictos, señalan que en la vida de un ser humano se conoce a varias personas (parejas), en cada ocasión crees que es la indicada, pero no es así. En este sentido se puede considerar como "más realista", porque "el amor se puede devaluar, es solo un mito, pero no lo hace falso, porque hay parejas que han demostrado estar juntas" (Lindsay, 19, Antropología); es decir, no en todos los casos funciona la eternidad del sentimiento. Algunas coinciden con sus pares masculinos señalando que nada dura para siempre. Otras atribu- yen a la temporalidad de las relaciones y a la falta de sinceridad de sus parejas.

d. ¿Crees que la infidelidad es un problema?, ¿qué harías si tu pareja te fuera infiel, perdonarías el hecho?

La mayor parte de los jóvenes no perdonarían la infidelidad, es una de las razones por la que se pierde la confianza dentro de la relación; consideran que dentro del amor debe existir exclusividad, no hay espacio para un tercero, también evocan a la mentira como algo que acompaña a la infidelidad.

Dentro de los testimonios, encontramos que algunos perdonarían este hecho, pero otros no, aunque solo la primera vez, en una segunda no. Lo que queda claro sobre la infidelidad es que es un motivo definitivo para terminar con la relación de pareja, los jóvenes se sienten traicionados en su confianza.

Las universitarias tienen una posición más firme, no tolerarían la infidelidad, por dignidad, por pérdida de confianza y por un recuerdo que se presentaría a cada momento en la relación. Si ha existido una infidelidad en la relación, ésta se evoca en cualquier momento y enseguida vienen las discusiones y peleas, lo que va quebrantando la relación. Las señoritas opinan que si una vez sucede la infidelidad, ellas no tienen ninguna seguridad que este hecho no vuelva a suceder, señalan que los hombres, si una vez fueron infieles, lo harán continuamente cada vez que se presente una oportunidad.

Algo que se manifiesta con insistencia, es que este hecho afecta emocionalmente a la persona que ha sido víctima de la infidelidad, la traición conlleva al sufrimiento y esta sensación se puede intensificar si la persona no supera este momento, es parte y característica del amor romántico que viven los jóvenes, la traición y el sufrimiento van juntos.

e. ¿Te separarías si supieras que tu pareja te fue o te es infiel? ¿Por qué?

Tabla 01. Muestra de respuestas de mujeres y hombres

\begin{tabular}{ccccc}
\hline & $\begin{array}{c}\text { Respuestas } \\
\text { de } \\
\text { mujeres }\end{array}$ & \% & $\begin{array}{c}\text { Respuestas } \\
\text { de } \\
\text { hombres }\end{array}$ & $\%$ \\
\hline Sí & 24 & $80.00 \%$ & 30 & $100.00 \%$ \\
No & 6 & $20.00 \%$ & 0 & $0.00 \%$ \\
\hline Total & $\mathbf{3 0}$ & $\mathbf{1 0 0 . 0 0 \%}$ & $\mathbf{3 0}$ & $\mathbf{1 0 0 . 0 0 \%}$ \\
\hline
\end{tabular}

Esta pregunta es de utilidad para confirmar los datos obtenidos de la pregunta anterior. La totalidad de los jóvenes se separarían de sus parejas por causa de la infidelidad, porque faltaría a la confianza y al respeto de la pareja; además, consideran que este comportamiento genera un daño sentimental en la pareja. 
Consideran que la infidelidad va acompañada de la mentira, existe una preocupación; "si lo hace descaradamente" lo que significa que lo público del tema importa mucho, que otros vean este comportamiento afectará el prestigio del joven con respecto a su pareja. Ellos lo ven por el lado que este hecho afecta directamente su hombría, no han sido capaces de mantener a su pareja a su lado y un tercero se los ha arrebatado.

También las señoritas, en forma unánime, señalan que en caso de infidelidad romperían con sus parejas, se repite la pérdida de confianza y respeto. La infidelidad es una prueba de falta de amor y de traición que origina que la pareja víctima de la infidelidad no vuelva a confiar. Es un comportamiento que siempre estará presente en la vida de la pareja (en caso que continuasen) y que no los dejará vivir su relación amorosa con tranquilidad. La parte femenina se inclina más a la perdida de la confianza, a algo que ellas no pudieron dar a sus parejas (hombres) y que éstos pudieron encontrar ese algo en otra persona. Si se reflexiona sobre este último mensaje se puede notar una cierta autoculpa de las señoritas por la que la relación no funcionó.

\section{f. ¿Por qué motivos una pareja se separaría? Mencione algunos.}

Existen distintos motivos por los que los jóvenes se separarían de sus parejas, las que resaltan son: falta de comprensión y amor, infidelidad, monotonía, aburrimiento, maltrato físico, incompatibilidad de caracteres, mentira y desconfianza.

Las que más se reiteran son la infidelidad, la incomprensión y la agresión. La infidelidad es el hecho que definitivamente tiene como consecuencia la separación de la pareja, en los jóvenes esta conducta de la pareja le trae un desprestigio frente a sus pares, cuestiona directamente la hombría de los jóvenes, nadie quiere ser la persona engañada; esto generaría habladurías, burlas y expresiones compasivas de su entorno frente al joven.

Otro motivo importante para separarse de la pareja, es la falta de comprensión, que está ligado a las peleas y hasta en un momento a las agresiones. Los pleitos pueden derivar de celos, malentendidos, orgullos, caprichos y otros.

Sin embargo, también es necesario tomar en cuenta las características como monotonía y aburrimiento, quizás porque se piensa que el amor debe ser siempre divertido, ideal y perfecto.

Para las señoritas, los motivos coinciden por los señalados por los universitarios; infidelidad, maltrato físico y psicológico, falta de comprensión y amor, falta de comunicación, cambios en la persona y falta de confianza. Uno de los elementos que ellas le atribuyen importancia es la falta de comunicación, de acuerdo a sus expresiones sus parejas son muy poco expresivos y lacónicos al momento de dirigirse a ellas; ellas pueden entender esta situación, pero cuando esto va acompañado a cambios de estado de ánimo, discusiones, celos y maltrato físico, aunque ellas señalan que son motivos suficientes para acabar con la relación, lo cierto es que si la relación tiene varios años de duración, es más complicada la separación.

g. ¿Qué opinión tienes de las personas que se casan, se divorcian, se vuelven a casar, o tiene varias parejas en su vida? ¿Por qué? Especificar en caso de los hombres y las mujeres.

Los jóvenes consideran que el divorcio se debe principalmente a la falta de madurez de la pareja, falta de diálogo, y trae como consecuencia el sufrimiento de la familia y especialmente de los hijos. Consideran que los hombres son muy volubles, no saben lo que quieren, tienen inestabilidad emocional. La inmadurez está relacionada al número de parejas que tienen a lo largo de su juventud, "teniendo mujeres que se les va apareciendo”. Para los jóvenes tener varias parejas en su juventud les significa un prestigio frente a sus pares. Se menciona el placer, antes que los sentimientos, esto ocurre cuando tienen muchas parejas, pero se considera peligroso este comportamiento porque les limita en su madurez y en tomar responsabilidades.

Las universitarias consideran que antes de casarse deben conocer bien a la otra persona, porque el matrimonio implica seriedad y compartir toda la vida con una persona. Dentro de algunos testimonios, se aprecia una tolerancia a este comportamiento, ya que si ocurre en distintos momentos, no tiene importancia porque está actuando lealmente, no se engaña a nadie, una chica puede comprometerse con un joven sin tener una relación actual, las experiencias anteriores no cuentan. También hay un grupo que consideran a las mujeres que tienen varios matrimonios como personas inmaduras debido a que estas personas temen la soledad, no pueden estar solas y necesitan que alguien les acompañen, éstas personas no aman de verdad, no están preparadas o se rehúsan a tener relaciones formales.

También se hace presente el discurso religioso cristiano, Dios no permite el divorcio, él aborrece la separación de las parejas; para estas encuestadas, el divorcio no existe de acuerdo a sus creencias, "lo que Dios ha unido que no lo separe el hombre”.

Los testimonios se pueden interpretar considerando que si lo ideal es ser maduro y responsable solo se puede tener una pareja, mantener el amor y el matrimonio, se continúa buscando idealizar la relación amorosa.

h. Según tus expectativas ¿a qué edad te casarías?, ¿a qué edad tendrías tu primer hijo?, ¿cuántos hijos desearías tener? ¿Por qué?

Los jóvenes consideran que la edad óptima para forma una familia es desde los 28 a los 32 años de edad, 
lo que coincide con la finalización de sus estudios, obtención de su diploma de profesional, y de un trabajo, ellos opinan que no es bueno formar una familia después de los 32 años porque ya eres muy maduro. La mayor parte de los encuestados consideran que entre dos o tres hijos es el número óptimo para su familia, aunque otra parte plantea una familia más numerosa, un caso desearía tener hasta un equipo de fútbol.

Respecto a las señoritas la edad coincide con los jóvenes entre los 28 y 30, ellas prefieren casarse, y dentro de un par de años concebir su primer hijo. Ellas prefieren prolongar su maternidad son conscientes que este acontecimiento les significará una dedicación que les restará posibilidades de seguir estudiando o trabajando, e incluso piensan en un tiempo de disfrute antes de ser madres.

También se preocupan de la alimentación, educación, y otros de sus hijos, por eso ellas prefieren formar una familia después de conseguir un trabajo para poder sostener a la familia. No sólo buscan una estabilidad económica, sino también en la parte afectiva y emocional.

Nuestra sociedad ha tenido un desarrollo de la familia, de hace 50 años, familia numerosa, donde prácticamente no existía el divorcio, hasta familias, con un mínimo de hijos o sin hijos. Aunque todavía no hemos llegado a los "dinks" (double income no kids, doble ingreso, no hijos).

Para los jóvenes, sobre todo para las señoritas, en las últimas décadas hay aspectos más importantes en su vida, educación, profesionalización y trabajo, aunque este hecho no ha eliminado la posibilidad de formar una familia al "modo tradicional”, de tener una pareja e hijos.

i. En el proceso de enamoramiento, las declaraciones, invitaciones, cortejo, ¿quién debe tener la iniciativa?, el hombre o la mujer, ¿Por qué?

La mayor parte de los encuestados, indican que es el hombre el encargado de tomar la iniciativa en una relación, señalando como razones; la confianza, madurez, caballerosidad y para que la relación tenga más formalidad; es decir, seriedad. Una minoría sostiene que pueden ser cualquiera de la pareja. Se aprecia que la persona que conduce la relación es el hombre, tiene un rol más protagónico y más activo frente a la mujer. Aunque los jóvenes, también señalan que pueden ser ambos porque de esa manera se hace querer con la otra persona. Puede estar sucediendo que las generaciones actuales de los jóvenes tienen mayor apertura a los sentimientos que las generaciones anteriores, igual son más comprensivos respecto a que las mujeres vayan ganando espacio en las relaciones amorosas con sus parejas, en este caso a tomar la iniciativa, a tener un rol más activo.

Las universitarias señalan que la iniciativa la pueden tener cualquier persona dentro de la pareja, sea el hombre o mujer, indistintamente, porque se imagina que ambos sienten los mismo, estas opiniones las sustentan ellas en la igualdad de género.

Algunas de ellas mantienen el discurso tradicional; "típicamente es el varón quien se supone debe tener la iniciativa, porque a través del tiempo eso nos han inculcado", la palabra clave para entender este testimonio es se supone, más adelante aclara, "pero actualmente se está dejando de lado esta costumbre”. Por otra parte, hay opiniones controvertidas, por un lado se señala que los hombres en su gran mayoría toman la iniciativa para empezar una relación amorosa, invitar a salir, una conversación, el primer beso, la primera agarrada de mano; sin embargo, también se señala "que hay algunas jovencitas" que toman la iniciativa en una relación sexual, y "no solo con una persona, sino con varias".

j. ¿Qué es lo que te atraería más de un joven o señorita (según las circunstancias) físico, personalidad, inteligencia, dinero?

Las características que más privilegian los jóvenes de acuerdo con las encuestas en las mujeres, son la personalidad, la inteligencia y su forma de ser. Es interesante ver que ellos se refieren al físico como una tercera o cuarta característica que aprecian en la amada. Esto contradice los estereotipos de belleza que impone la sociedad moderna actual, sobre todo cuando se objetiviza a la mujer y se privilegia su físico.

Las mujeres señalan que lo primero que les atrae de un hombre es su personalidad, que sean respetuosos y caballeros, que puedan mantener una conversación interesante, luego su inteligencia, aunque también destacan los sentimientos, las señoritas desean una persona a su lado que tenga la capacidad de sentir, esto es importante, porque tradicionalmente el lado masculino se consideraba más racional que sentimental (que es o era una característica femenina). Las señoritas son más sinceras al señalar que lo primero que ellas aprecian es el físico, es la primera impresión que ellas tienen de la persona que se les acerca.

Al procesar esta pregunta se nota que las mujeres describen a la personas sobre las que ellas se fijarían con mucho mayor detalles, enumeran las características y son más explicitas que los jóvenes.

\section{k. ¿Cuál es el modelo físico de la mujer que atrae a los hombres en nuestra sociedad local?}

Esta pregunta tiene relación con la anterior, aunque las opiniones en este caso más se centraron en el aspecto físico, mientras que en la anterior pregunta más fue en la personalidad y la inteligencia.

Se puede realizar una interpretación a partir de los 
testimonios de las señoritas. Ellas le dan mucha importancia a elementos específicos como el cabello bien cuidado, un elemento que define su feminidad, también hacen referencia algunos términos como fitness, que lo conciben como estar en buena forma, coinciden en aspectos como delgada y alta, buenas medidas, voluptuosas, buenos pechos, un testimonio refiere que el hombre busca este tipo de mujeres para presumir entre sus amigos.

Los testimonios de los jóvenes señalan que es necesario el buen cuerpo (lo que implica buenas nalgas y pechos), delgadas altas y blancas. Llama la atención un testimonio, en la cual señala que hable bien el castellano y que tenga una buena posición económica, lo que va más allá del aspecto físico, sino que busca cualidades socialmente valorizadas; la economía y la forma de hablar el castellano. Los testimonios de los universitarios (as) coinciden que estos modelos, son transmitidos por los medios de comunicación. Los estándares de belleza internacionales han triunfado en este sentido.

\section{Sexualidad}

\section{a. ¿Cuán importante son las relaciones sexuales} (coitales) en una pareja?

Tabla $\mathbf{N}^{\circ}$ 02. Importancia de las relaciones sexuales en una pareja

\begin{tabular}{ccccc}
\hline & $\begin{array}{c}\text { Respuestas } \\
\text { de } \\
\text { mujeres }\end{array}$ & \% & $\begin{array}{c}\text { Respuestas } \\
\text { de } \\
\text { hombres }\end{array}$ & $\%$ \\
\hline $\begin{array}{c}\text { Muy } \\
\text { importante } \\
\text { Importante }\end{array}$ & 12 & $40.00 \%$ & 18 & $60.00 \%$ \\
$\begin{array}{c}\text { No es } \\
\text { importante } \\
\text { Nada } \\
\text { importante }\end{array}$ & 6 & $33.33 \%$ & 9 & $30.00 \%$ \\
\hline Total & 2 & $20.00 \%$ & 3 & $10.00 \%$ \\
\hline
\end{tabular}

La mayor parte cree que las relaciones coitales son muy importantes, aquí entra en concordancia con los discursos sobre la sexualidad expuestos por Fuller (2001), aunque en esta ocasión los jóvenes creen que es necesario para la relajación y liberar sobretensiones y estreses, los jóvenes se encuentran preocupados por diversos motivos de índole académico (estudios), familiares, económicos y otros, entonces el sexo con sus parejas les ayuda a aliviar sus preocupaciones. Una minoría considera que es una actividad complementaria porque lo más importante es el amor entendido como un sentimiento puro. Además, según ellos, estas relaciones fortalecen el amor entre ellos.

La amplia mayoría de las universitarias creen que las relaciones sexuales - coitales son muy importantes dentro de una relación, para ellas es una forma de de- mostrar el amor, además señalan que la intimidad de la pareja permite que las relaciones sean más duraderas. Este hecho se puede sintetizar en el siguiente testimonio: "Toda pareja necesita un tiempo de pasiones, para demostrar su amor" (Beatriz, 21, Antropología)

Estos testimonios contradicen los planteamientos tradicionales sobre las mujeres respecto al sexo, que consideran a las mujeres recatadas, pasivas, que solo esperan la iniciativa de sus parejas y que les avergüenza hablar de estos temas y demostrar interés por la relación.

\section{b. ¿Cuán importante son los sentimientos en} una pareja?

Dentro de las relaciones amorosas se considera dos aspectos que sobresalen, el lado sexual y el lado sentimental; con la pregunta, se pretendió buscar el cómo consideran el lado sentimental los jóvenes.

Los universitarios señalan que es importante o muy importante este aspecto, este lado de la relación les permite "abrirse"; es decir, ser sinceros contando todos sus sentimientos, felicidades, miedos y sueños. También fortalece la confianza y el respeto con la pareja y permite evitar problemas futuros e incluso señalan que depende de este aspecto la relación. Según una afirmación: "Es un elemento que no debe faltar en las relaciones" (Ed, 24, FIEE)

Las señoritas, también consideran muy importante este aspecto, es la base fundamental donde descansa la relación amorosa y son los que dirigen el respeto, afecto y protección porque depende de ellos (sentimientos) que una relación marche bien, pero estos sentimientos tienen que ser sinceros, esta frase permite entender que muchas de ellas dudan de la sinceridad de sus parejas; además, ellas contraponen los sentimientos a la atracción física consideran que los primeros son más importantes. Finalmente, los sentimientos sinceros posibilitarán que la relación sea armoniosa y que cada uno de ellos se sienta bien y a gusto con la pareja.

A través de los testimonios podemos ensayar dos interpretaciones: la primera, los hombres están acercándose cada vez más al aspecto sentimental, antes considerado como característica de la feminidad; y la segunda, se refuerza la característica romántica y sentimental del amor de pareja.

c. ¿Quién debe tener la iniciativa en las relaciones sexuales, el hombre o la mujer, por qué?

Respecto a quien debe tener la iniciativa en la relación sexual, los jóvenes sugieren que deben ser ambos, cualquiera de los dos, porque entre ellos debe existir una gran confianza y deben tener una gran conexión para llegar al clímax. También se señala que el deseo puede ser en cualquier momento, es un momento mágico, por lo que cualquiera puede tomar la iniciativa y 
el deseo puede provenir de cualquiera y esa persona en ese momento debe proponer a su pareja la respectiva relación. Aunque unos pocos se amparan en la biología, "el hombre porque según el caso hormonal es él quien tiene más deseo que las mujeres” (Ed, 24, FIEE).

Las señoritas también coinciden que puede ser cualquiera de los dos en la pareja, porque son iguales y ambos lo desean, se reitera el tema de la confianza. Se menciona el tema de la igualdad y la ocasionalidad, puede ser en cualquier momento ambos tiene la capacidad de proponerlo y hacerlo.

También, se menciona que la mujer llega a tener confianza y seguridad en la intimidad después de algunos años con su pareja, es en ese momento que puede pedirle algunas cosas referidas a las relaciones sexuales. Muchas de ellas están convencidas que puede ser el hombre o la mujer, pero también señalan "cualquiera podrá tener la iniciativa, pero se ha visto que de la iniciativa es el varón, pues en una mujer es mal visto" (Melany, 20, Antropología)

En los dos géneros se indica que pueden ser ambos quienes pueden tener la iniciativa, aunque se mantiene una minoría que considera que la iniciativa la debe tener el varón.

\section{d. ¿Eres celoso, celosa?}

Una mayoría de los encuestados reconocen que son celosos, incluso utilizan el término "mucho", una minoría dicen que son celosos, pero "poco", reconocen que es por miedo a perder la pareja, o señalan que el que ama tiene que ser celoso, aunque sea moderadamente, un testimonio señala "si y quiero a una mujer tiene que ser solo mía” (Yefere, 22, Ing. Metalurgia), se muestra la intención de propiedad dentro de la relación. Los que indican que son poco celosos señalan como argumentos que la confianza es primero e incluso cuando sospechan de una infidelidad hay que actuar en forma inteligente.

e. ¿Llamas a tu pareja por el celular al día? Tema de conversación

La idea de esta pregunta es conocer si existe un control por parte del hombre hacia su pareja o viceversa, a través del celular. De acuerdo a algunas versiones de los jóvenes es poco, para saber cómo esta ella, cómo se siente o si hay algo pendiente para conversar. Otros testimonios manifiestan que llaman a sus parejas varias veces. Los temas de conversación son problemas de familia, trabajo, amigos, cómo le fue en el día, hacer planes para salir y otros.

f. ¿Permitirías a tu pareja que vaya solo o sola a fiestas nocturnas? ¿Por qué?

Las opiniones al respecto están divididas hay jóvenes que si permitirían que sus parejas salgan de noche solas, mientras que otros no. Los que están de acuerdo sustentan sus opiniones en la confianza, pero la señorita debe de tener cuidado y sobre todo debe ir con personas conocidas. Los que no están de acuerdo en que salga su pareja de noche y sola fundamentan lo siguiente: de noche es muy peligroso, le puede pasar algo malo, además ella no quería, sin él estaría aburrida.

En relación a las mujeres, ellas si están de acuerdo que sus parejas pueden salir de noche, los motivos que señalan son la confianza, cada persona debe de tener su espacio y saber divertirse, también cada uno debe respetar las decisiones del otro y ser sincera si no le gusta alguna actitud de él.

g. ¿Alguna vez has revisado el celular de tu pareja? ¿Por qué?

Sobre si han revisado el celular de sus parejas las opiniones están divididas, los que aceptaron que revisan los celulares de sus parejas fue porque su pareja le permitió hacerlo, otros lo hacen por curiosidad, saber las conversaciones en Facebook. Mientras que los que no lo hicieron, es que consideran que el celular es personal y que nunca se debe enseñar a la pareja. También hay otros que dicen que son sus mismas parejas las que les muestran el celular. Algo similar sucede con los testimonios de las señoritas, indican que no, porque ellas confían en sus parejas y los celulares son objetos personales; además, no hay necesidad de hacerlo. Por otro lado, Si porque existe la curiosidad de ellas de revisar, aunque solo fueron unas cuantas veces.

\section{DISCUSIÓN}

\section{Sobre el amor}

a. ¿Cómo concibes el amor de pareja? (definición)

Se mantiene la figura del marianismo en algunos aspectos en la definición del amor, como por ejemplo, el sacrificio y la abnegación más no así otras características de este modelo de feminidad como son la castidad y la negación sexual, como se verá más adelante.

b. ¿Crees que el amor de pareja es exclusivo (solo se puede amar a una pareja) o se puede amar a otras personas?

Las relaciones sexuales están reguladas en nuestra sociedad lo que predomina es la monogamia heterosexual, aunque las investigaciones antropológicas han descubierto una serie de formas y variantes que las personas tienen para relacionarse sexualmente. Por ejemplo, Mead (2014), señala que existía una permisividad sexual entre las adolescentes de Samoa; además, que ellas tenían sexo casual a temprana edad, estos hallazgos la investigadora lo contrasto con la realidad de la juventud norteamericana de mitad del siglo XX.

c. ¿Crees que amor es para siempre, "hasta que la muerte los separe? ¿Por qué?

Esta frase es parte del discurso religioso católico, 
que se interpreta que lo que Dios unió, el hombre no lo separará, refiriéndose al matrimonio es parte de la sacralización de esta institución; sin embargo, los jóvenes opinan que el amor es temporal porque cumple un ciclo, aunque puedan existir parejas que persistan en su relación a través de los años. Siguiendo a Bauman (2005), vivimos una época en que lo común es enamorarse y luego desamorarse, y volver a enamorarse, siguiendo un ciclo casi interminable, la facilidad de los sujetos que encuentran una pareja y luego terminan, el amor líquido.

d. ¿Crees que la infidelidad es un problema?, ¿qué harías si tu pareja te fuera infiel, perdonarías el hecho?

Al respecto Luhmann (1984), indica que el amor pasión conlleva el virus de la infidelidad, aclara que el amor es algo místico entregarse plenamente al otro, la exclusividad radica en el marco del código porque nadie podría entregarse plenamente a varios amantes sin poder multiplicarse, ese es el mensaje de exclusividad que deja el amor romántico.

e. ¿Te separarías si supieras que tu pareja te fue o te es infiel? ¿Por qué?

Fuller (2001), de acuerdo a su investigación concluye que la infidelidad es aceptable en el varón e inadmisible en las mujeres, aunque un número no desdeñable de jóvenes considera que ambos géneros son dueños de sus cuerpos y deseos. Puede ser como plantea la autora aceptable e inadmisible, pero lo que señalan los jóvenes es que si se separarían de sus parejas por esta causa. Las jóvenes no aceptan la infidelidad de sus parejas, quizás la perdonen con algunas consecuencias no gratas para la pareja como se ha indicado en la parte superior.

f. ¿Por qué motivos una pareja se separaría? Mencione algunos.

Se aprecia que el mensaje de la no agresión en ninguna forma a la pareja va consiguiendo resultados, aunque que sea solo en las declaraciones, en las generaciones más jóvenes, lo que quizás no se presentaba en las anteriores generaciones, que incluso se manifiesta que si la pareja no te pegaba no te quería, ese mensaje, hoy en día es insostenible.

g. ¿Qué opinión tienes de las personas que se casan, se divorcian, se vuelven a casar, o tiene varias parejas en su vida? ¿Por qué? Especificar en caso de los hombres y las mujeres.

Para Bauman (2005), en la actualidad, las parejas sexuales solo buscan satisfacer sus ganas, es algo momentáneo que infunde la esperanza que no habrá consecuencias duraderas para buscar otros momentos más satisfactorios y plenos. El deseo ortodoxo necesita atención y preparativos implica también una demora de la satisfacción que es sin duda el sacrificio más aborrecido en nuestro mundo entregado a la velocidad y aceleración. La realidad nos demuestra que las parejas mayormente son temporales, incluso es popular la frase: "choque y fuga" o "un rapidín” entre los jóvenes; sin embargo, esto comportamiento es sancionado por el colectivo social, con los calificativos de inmadurez, falta de autoestima o traición.

h. Según tus expectativas ¿a qué edad te casarías?, ¿a qué edad tendrías tu primer hijo?, ¿cuántos hijos desearías tener? ¿Por qué?

Fuller (2001), señala que la masculinidad es una construcción social, es un proceso continuo durante toda la vida del hombre, que tiene hitos importantes que casi definen la hombría y la virilidad los que son el matrimonio y tener hijos, sobre todo hombres, que continúen o perennicen el apellido del padre, de allí la necesidad de los hombres de casarse y tener hijos. La misma investigadora considera que la maternidad es considerada el pilar de la identidad femenina, también anota que este es uno de los aspectos que más ha cambiado durante los últimos años, las mujeres ya no quieren tener muchos hijos, en algunos casos prefieren postergar la maternidad. Las feministas como Simone de Beauvoir, Nancy Chodorow y Ortner, citadas por Moncó (2011), señalan que la maternidad es la institución que históricamente ha relegado a las mujeres a un segundo plano.

i. En el proceso de enamoramiento, las declaraciones, invitaciones, cortejo, ¿quién debe tener la iniciativa?, el hombre o la mujer, ¿por qué?

Fuller (2001), señala que todavía persiste la norma que estipula que corresponde al varón tomar la iniciativa en las relaciones sexuales. En este punto Esteban (2011) manifiesta que en el campo de la sexualidad, tanto el hombre como mujer, aparecen como sujetos deseados y deseantes, aunque la iniciativa y el saber sexual siempre aparezcan como saberes masculinos. Las generaciones jóvenes van tomando la iniciativa en base a la confianza que ellas van ganando en las relaciones amorosas. Otro elemento que se debe considerar, son los mensajes educativos de igualdad y equidad entre hombre y mujer que son difundidos a través distintos medios. Esta información es parte de un proceso histórico; a decir de Morán (2013), es parte del reconocimiento de los derechos sexuales y reproductivos. En la universidad los discursos de igualdad de género van llegando poco a poco las mujeres se van sintiendo empoderadas.

j. ¿Qué es lo que te atraería más de un joven o señorita (según las circunstancias) físico, personalidad, inteligencia, dinero?

En las respuestas se nota la idealización del amor, personalidad, respeto y caballerosidad, lo que para muchas feministas esto conduce a ser las guardianas, 
las responsables de los sentimientos, lo que al mismo tiempo sirve para justificar su subordinación (Esteban, 2011). En la investigación faltó identificar y desarrollar lo que los jóvenes entienden por personalidad.

k. ¿Cuál es el modelo físico de la mujer que atrae a los hombres en nuestra sociedad local?

Al respecto Kogan (2009), cuando realiza su investigación sobre el cuerpo en la clase alta limeña, señala que para las mujeres, la apariencia física tiene mucha importancia, es un elemento de preocupación constante. Las razones por las que creen que deben cuidar su apariencia física son las de sentirse bien ellas mismas y ser bien consideradas por el marido y los hijos, el cuerpo es fuente de autoestima.

\section{Sexualidad}

a. ¿Cuán importante son las relaciones sexuales (coitales) en una pareja?

Giddens (2012), concluye que hoy en día, por primera vez en la historia, las mujeres exigen igualdad a los hombres en el campo sexual. A través de la investigación se nota que las jóvenes van ganando terreno en este campo no lo han hecho de manera radical, pero si lo están haciendo de manera paulatina.

b. ¿Cuán importante son los sentimientos en una pareja?

Contradice lo que señala Ruíz (2001), cuando manifiesta que la construcción de la masculinidad implica la represión y el desarrollo de emociones, sentimientos y valores considerados femeninos, parece que es una interpretación mecánica de los estudios de género tradicionales (mujer - sentimiento y hombre - razón) los jóvenes no se avergüenzan de ser afectivos con sus compañeras.

c. ¿Quién debe tener la iniciativa en las relaciones sexuales, el hombre o la mujer por qué?

Respecto a la sexualidad Ruíz (2001), considera que hay una exacerbación de la sexualidad masculina, unida al desarrollo de una pasividad femenina, los resultados muestra algo distinto, las jovencitas cada vez van tomando la iniciativa, hay que señalar que es un ámbito de intimidad y confianza con sus parejas.

\section{d. ¿Eres celoso, celosa?}

Los testimonios recogidos de las señoritas son más variados, algunas indican mucha, otras poco, y algunas "para nada". Se manifiesta que los celos son producto de la inseguridad y que cada uno debe respetar el espacio del otro, lo que refleja la independencia de las personas. Otras se reconocen celosas, pero prefieren ocultarlo y no demostrarlo. Los motivos para los celos son parecidos a sus pares del otro género, los celos son porque te importa la otra persona. Lo contrario a los celos es la seguridad y la confianza que tienen con sus parejas.

e. ¿Llamas a tu pareja por el celular al día? Tema de conversación

Los testimonios de las señoritas también se encuentran equilibrados entre varias veces o pocas veces. En la que respecta a varias veces, cómo le va en su trabajo, cómo le fue en día, cómo está la familia, que dificultades tuvo en el día. Pocas veces, algunas novedades, lo que hizo en el día y lo que podemos hacer nosotros después. Los temas coinciden, lo que se observa es que las parejas al momento de llamar, la primera conversación son dos preguntas que se repiten: ¿Dónde estás? y ¿Qué haces?

f. ¿Permitirías a tu pareja que vaya solo o sola a fiestas nocturnas? ¿Por qué?

Se nota el rol protector del hombre frente a la mujer, es muy inseguro para ellas salir de noche y solas, en cambio a los hombre no les pasa nada.

g. ¿Alguna vez has revisado el celular de tu pareja? ¿Por qué?

Hay opiniones divididas entre si y no, la confianza y desconfianza, credibilidad e incredulidad de permitir que revisen sus celulares sus parejas, a veces también lo hacen por casualidad, cuando le prestan para hacer algunas llamadas porque se quedaron sin saldo, y/o curiosidad de saber algo más. Se ha percibido que los jóvenes de hoy no pueden vivir sin el celular, y están ensimismados en los modelos, aplicaciones y uso desmesurado; si bien es cierto, es un medio de comunicación pero viene creando dependencia y riesgos para el bienestar físico y mental.

\section{CONCLUSIONES}

- De acuerdo a las opiniones de los jóvenes, consideran al amor como algo temporal, no creen que sea eterno, o dure para siempre; para ellos y ellas, es un aspecto de la vida social que tiene un principio y un fin, por las circunstancias y contingencias diversas de la vida, ya que los seres humanos se mueven en un mundo de la relatividad, intereses y conveniencias.

- Ambos géneros consideran el aspecto sexual (placer, físico) y el sentimental como elementos importantes y necesarios dentro de una relación amorosa. El primero, porque libera tensiones entre los jóvenes y es una necesidad de ambos y; el segundo, porque es la base de la relación, pero tiene que ser sincero sobre todo de la parte de los hombres. No olvidemos somos seres sensibles con emociones, concepciones, admiraciones, anhelos de encontrar su contraparte.

- Dentro de la relación amorosa se prioriza la personalidad y la inteligencia de las parejas para ambos. 
Aunque algunas de ellas consideran si la relación va a ser temporal priorizan el físico. Pero a través de la observación y los testimonios personales de los jóvenes, ellos priorizan el físico, sobre todo las caderas y el rostro de las señoritas.

- Respecto a la iniciativa en la relación amorosa, pueden ser ambos los que tomen la iniciativa; sin embargo, se prefiere que sea el hombre por caballerosidad y para que la relación tenga mayor seriedad. Sobre las relaciones sexuales, coitales, se manifiestan que pueden ser ambos, aunque la mujer solo se siente en confianza después de algún tiempo con su pareja, recién en ese momento puede pedir "algunas cosas", pero algunos testimonios refieren que hay señoritas que toman la iniciativa. Se nota que en este aspecto las mujeres van dejando el tradicional papel pasivo para tener uno más activo, "los tiempos han cambiado", ya hoy en día el enamoramiento y comportamiento sexual no es tan rígido como antes.

- El tema de la infidelidad es imperdonable, dentro de la relación es motivo para un rompimiento definitivo, es considerada como traición a la confianza de la pareja. Otros motivos para la separación son las discusiones, incompatibilidad de caracteres, maltrato físico y psicológico, consideran si la relación tiene años de duración más difícil es la separación.

- Se manifiestan los celos y la posesión entre los jóvenes, a través del control del cuerpo, revisando los celulares de las parejas, no permitiendo que salgan solas, según ellos la sociedad es peligrosa, para evitar que sus enamoradas corran peligro si salen solas. Muchos de los jóvenes no se han enamorado una sola vez sino muchas veces y no siempre se unieron en matrimonio con la primera enamorada(o).

\section{REFERENCIAS BIBLIOGRÁFICAS}

Bauman, Z. (2005) Amor líquido. Acerca de la fragilidad de los vínculos humanos. $1^{\circ}$ ed. FCE. Argentina 203 pp.

Carmona, M. (2011) “ ¿Negocian las parejas su sexualidad? Significados asociados a la sexualidad y prácticas de negociación sexual” Revista Estudios Feministas. Brasil 21 pp.

Danziato, L. (2016) "From de sexual difference to sexuation” Revista Agora. Rio de Janeiro. 14 pp.

Di Gerónimo (2012) El amor cortés. Escenas amorosas que sostienen el mundo CILHA. Argentina. $17 \mathrm{pp}$.

Esteban, M. (2011) Crítica del pensamiento amoroso. Ed. Bellaterra. $1^{\circ}$ ed. Barcelona 498 pp.

Hernández, R., Fernández, C. y Baptista, P. (2010) Metodología de la investigación. México. Ed. Mc Graw Hill.
Fuller, N. (2002) Masculinidades, cambios y permanencias $1^{\circ}$ ed. PUCP. Lima - Perú. 510 pp.

Giddens, A. (2012) La transformación de la intimidad. Sexualidad, amor y erotismo en las sociedades modernas. $7^{\circ}$ ed. Cátedra editorial. España 185 pp.

Guash, O. (2006) Héroes, científicos, heterosexuales y gays. $1^{\circ}$ ed. Ediciones Bellaterra. España 160 pp.

Malo, A. (2004) Antropología de la afectividad, $1^{\circ} \mathrm{ed}$. EUNSA editorial. Navarra - España 238 pp.

Mead, M. (2014) Sexo y temperamento en tres sociedades primitivas $3^{\circ} \mathrm{ed}$. Paidós editorial. Barcelona España 308 pp.

Moncó, B. (2011) Antropología del género $1^{\circ}$ ed. Síntesis editorial. $245 \mathrm{pp}$.

Morán, J. (2013) “Feminismo, iglesia católica y derechos sexuales y reproductivos en el Chile post dictatorial" Revista Estudios Feministas. Brasil 24 pp.

Morris, D. (2005) El mono desnudo. $5^{\circ}$ ed. De bolsillo, editorial. Barcelona 269 pp.

Nugent, G. (2010) El orden tutelar. Sobre las formas de autoridad en América Latina, $1^{\circ}$ ed. CLACSO editorial. Lima - Perú. 165 pp.

Lipovetsky, G. (2009) El amor posromántico. En amor y poder, $1^{\circ}$ ed. Fondo editorial del congreso del Perú, editorial. Lima - Perú 280 pp.

Luhmann, N. (1984) El amor como pasión. La codificación de la intimidad $1^{\circ}$ ed. Península editorial. Barcelona 154 pp.

Rackley, L. (2016) "Book review: bad girls: young women, sex and rebellion before the sixties" Journal of international women's studies. USA. 3 pp.

Ruíz, P. (2001) “Género y masculinidades”. En Subversiones masculinas. Imágenes del varón en la narrativa joven, editorial Flora Tristán. Lima - Perú 40 pp.

Tarrés, M. A propósito de la categoría género: leer a Joan Scott Estudios Sociológicos [en linea] 2013, XXXI (Enero-Abril): [Fecha de consulta: 4 de junio de 2017] Disponible en:<http://www.redalyc.org/ articulo.oa?id=59830136001 $>$ ISSN 0185-4186

Vich, V. (2001) El discurso de la calle. $1^{\circ}$ ed. Red para el desarrollo de las ciencias sociales en el Perú. Lima - Perú. 193 pp.

Zizek, S. (2009) El acoso de las fantasías. $3^{\circ}$ ed. Siglo XXI editorial. Madrid. 260 pp. 